\title{
Magnitude Studium: um micromundo para o ensino de área e perímetro
}

Magnitude Studium: a microworld for area and perimeter teaching

\author{
Anderson Douglas Pereira Rodrigues da Silva ${ }^{1}$ \\ Franck Gilbert René Bellemain²
}

\section{Resumo}

Esta pesquisa tem como objetivo explicitar uma parte do percurso de concepção e desenvolvimento de um micromundo denominado de Magnitude Studium (MS), que foi desenvolvido e validado em nossa tese de doutorado (SILVA, 2019), como um suporte ao professor para o ensino de área e perímetro. A fundamentação teórico-metodológica contou com os pressupostos da Engenharia Didático-Informática desenvolvida por Ricardo Tibúrcio que alia aspectos da Engenharia Didática estudada e divulgada por Michele Artigue à Engenharia de Software explanada nos textos de Roger S. Pressman. Nela, discutimos a abordagem de área como grandeza das pesquisadoras francesas Régine Douady e Marie-Jeanne Perrin-Glorian. Em seguida, realizamos uma revisão de literatura com pesquisas nacionais que vêm corroborando com esse tratamento. Tal estudo nos permitiu elencar requisitos pertinentes ao novo micromundo para o ensino e aprendizagem de área e perímetro. Por fim, apresentamos a primeira versão do protótipo, o funcionamento de suas ferramentas e menus, como também, seu diferencial em relação a um software de geometria belga intitulado de Apprenti Géomètre 2 do qual vem nossa motivação para o desenvolvimento do MS.

Palavras chave: Área; Engenharia Didático-Informática; Engenharia de Software Educativo.

\section{Abstract}

This research aims to explain a part of the path of conception and development of a micro world called Magnitude Studium (MS) that was developed and validated in our doctoral thesis (SILVA, 2019), as a support to the teacher for teaching in the area and perimeter. The theoretical and methodological foundation relied on the assumptions of Didactic-Informatics Engineering developed by Ricardo Tibúrcio that combines aspects of Didactic Engineering studied and disseminated by Michele Artigue with Software Engineering explained in the texts of Roger S. Pressman. In it, we discuss the area approach as magnitudes of the French researchers Régine Douady and MarieJeanne Perrin-Glorian. Then, we conducted a literature review with national surveys that have corroborated this treatment. This study allowed us to list requirements relevant to the new micro world for the teaching and learning of area and perimeter. Finally, we present the first version of the prototype, the operation of its tools and menus, as well as its differential in relation to a Belgian geometry software entitled Apprenti Géomètre 2 from which our motivation for the development of MS comes.

Keywords: Area; Didactics-Computer Engineering; Educational Software Engineering.

\footnotetext{
${ }^{1}$ Faculdade de Ciências e Tecnologia Professor Dirson Maciel de Barros | anderdouglasprs@gmail.com

${ }^{2}$ Universidade Federal de Pernambuco | f.bellemain@gmail.com
} 


\section{Introdução}

Nossa tese de doutorado (SILVA, 2019), da qual o estudo aqui apresentado é um recorte, teve como objetivo conceber, desenvolver e validar um micromundo como elemento de suporte ao professor para o ensino de área e perímetro. A mesma dá continuidade a um conjunto de pesquisas que vêm sendo desenvolvidas ao longo dos anos pelos grupos LEMATEC (Laboratório de Educação Matemática e Tecnológica) ${ }^{3}$ e Prógrandezas ${ }^{4}$, ambos da Universidade Federal de Pernambuco.

A participação do pesquisador nesses grupos de estudo resultou na produção de uma dissertação de mestrado (SILVA, 2016), que teve como objetivo investigar o tratamento dado por estudantes de 12 a 13 anos do $6^{\circ}$ ano do ensino fundamental a um conjunto de tarefas sobre área em três ambientes distintos: papel e lápis, materiais manipulativos e o Apprenti Géomètre 2 (Aprendiz de Geometria). Este último é um software de geometria belga, desenvolvido pelo Centre de Recherche sur l'Enseignement des Mathématiques ${ }^{5}$ (CREM).

Os estudantes do $6^{\circ}$ ano que utilizaram o Apprenti Géomètre 2 como possibilidade de manipular uma pluralidade de recursos fornecidos nesse software, apresentaram um avanço na superação da "concepção geométrica de área" que se caracteriza por um amálgama entre a figura e a área, ou seja, para os sujeitos que mobilizam uma concepção geométrica é como se a palavra área remetesse à própria figura e não a uma propriedade da mesma (FERREIRA; BELLEMAIN, 2013).

Embora este software tenha se mostrado um importante recurso por oferecer condições que permitiram a mobilização de diferentes tipos de estratégias de resolução de tarefas sobre área de figuras planas, algumas limitações foram identificadas no decorrer do experimento da nossa pesquisa (SILVA, 2016), como também nas oficinas e minicursos ministrados pelo autor deste estudo em parcerias com (SANTANA; SILVA; BARROS, 2016). As limitações identificadas são de diferentes naturezas e podem não favorecer a construção de situações de aprendizagem de área e perímetro neste ambiente, como também restringir as ações de estudantes na resolução das tarefas de área e perímetro. Dentre elas, destacamos as seguintes:

- a maneira que o AG 2 lida com a decomposição exige do usuário uma combinação de procedimentos que não se mostraram ser intuitivos;

- as partes de uma figura decomposta só podem recompor uma nova se coincidirem seus vértices e suas arestas;

- o uso das malhas restringe-se apenas à pontilhada quadrada e à isométrica;

- o software permite apenas o trabalho com unidades de medidas não convencionais;

\footnotetext{
${ }^{3}$ LEMATEC: Grupo de pesquisa da UFPE liderado pelo professor Franck Bellemain, registrado no CNPq (Portal do LEMATEC, 2019).

${ }^{4}$ O grupo Pró-grandezas: ensino-aprendizagem das grandezas e medidas, da Universidade Federal de Pernambuco, certificado no diretório de grupos de pesquisa do CNPq, é liderado pelos professores Paula Baltar e Paulo Figueiredo Lima.

${ }^{5}$ O CREM é um grupo de pesquisa responsável pelo projeto de elaboração do Apprenti Géomètre nas versões 1 e 2. O projeto de desenvolvimento desse software contou com a participação dos seguintes integrantes: Michel Ballieu, Marie-France Guissard, Guy Noël, Nicolas Rouche et Marie-Françoise Van Troeye. Este Centro está localizado na 5 rue Émile Vandervelde, B-1400 Nivelles, Belgique.
} 
- o trabalho com ladrilhamento no AG 2 restringem-se ao uso de unidades de medidas não convencionais que estejam predefinidas em seus menus;

- Não há ferramentas específicas para o trabalho com perímetro de figuras planas.

As potencialidades e limitações encontradas nos resultados de nossa pesquisa (SILVA, 2016) nos permitiram refletir sobre a necessidade de se ampliar o trabalho com área e perímetro de figuras planas a partir do desenvolvimento de um novo software de geometria acessível ao professor $^{6}$ que permitisse a construção de situações de aprendizagem desses conceitos. Com relação ao tipo de software, decidimos desenvolver um micromundo pelo fato de ser um ambiente de simulação pedagógico projetado para apresentar propriedades que favorecem a modelagem de um domínio especificamente adaptado a alguma aprendizagem direcionada, com características como reversibilidade de ações, repetição de sequências ou análise a posteriori de ações realizadas ${ }^{7}$ (TCHOUNIKINE, 2011- grifo nosso).

Neste artigo, por se tratar de um recorte da nossa tese (SILVA, 2019) explicitamos uma parte do percurso de concepção e desenvolvimento do Magnitude Studium. Este texto está organizado em quatro seções divididas em duas etapas. A primeira, denominada de Dimensão Teórica, contempla a fundamentação teórico-metodológica para a concepção do software. A segunda etapa, caracterizada por Dimensão Operacional, diz respeito ao desenvolvimento e análise do funcionamento do micromundo. Por fim, temos as considerações finais e referências.

\section{Dimensão Teórica}

\section{A Engenharia Didático-Informática}

Para desenvolver este novo micromundo, ancoramo-nos em um método de desenvolvimento de software concebido nos estudos de Tibúrcio (2016), organizado em seis etapas, são elas:

i) Delimitação do campo: Tal delimitação define o campo de conceitos matemáticos a ser abordado pelo software.

ii) Análises preliminares: Nesta fase o objeto matemático a ser abordado pelo software é situado no contexto das pesquisas já realizadas, abordando-se os aspectos cognitivos, didáticos, epistemológicos e informáticos relacionados ao objeto. Os resultados desta análise fundamentam as principais necessidades do software.

iii) Análise de requisitos: Tal análise tem por objetivo "traduzir" as necessidades geradas na fase anterior em ferramentas e características do

\footnotetext{
${ }^{6}$ Um software que não seja complexo em ferramentas, numa linguagem que o professor dos anos iniciais ao ensino médio mesmo que não tenha familiaridade com artefatos tecnológicos digitais possa utilizar de forma a aprimorar o ensino e aprendizagem dos conceitos de área e perímetro.

${ }^{7}$ Microwords: Simulation or virtual reality pedagogical environments, i.e., software allowance learners to immerse themselves in a virtual word designed so as to present properties that will favor the adressing of the targeted pedagogical objectives: modeling of a domain specifically adapted to some targeted learning, taking advantage of features such as reversibility of actions, replay of sequences or a posteriori analises; etc. Tchounikine (2011, p. 2).
} 
software, ou seja, os requisitos do sistema são definidos com base nos resultados das análises preliminares.

iv) Análise a priori e prototipação: Nesta fase se dão o desenvolvimento do protótipo e a análise a priori, ou seja, uma análise das situações de uso e dos possíveis problemas que possam decorrer da utilização do software, a fim de corrigi-los.

v) Fase experimental (teste piloto, com professores, com alunos): Após o desenvolvimento do protótipo, se dá a fase experimental, na qual ocorrem os testes do software com os sujeitos destinados ao seu uso, como professores e estudantes, antecedidos por um teste piloto que pode gerar necessidades de ajustes.

vi) Análise a posteriori e validação: Esta fase tem por objetivo analisar, com base nos testes do software e em comparação com a análise a priori, se os objetivos estabelecidos para o software foram alcançados, resultando na validação do software. (SILVA CÉSAR, 2016, p. 25-27).

Esse método vem sendo utilizado por pesquisadores do grupo de estudos LEMATEC e tem contribuído para o desenvolvimento de artefatos digitais, como o software Function Studium, um micromundo desenvolvido para o estudo de funções numéricas (SILVA CÉSAR, 2016) e o Cônicas, um software que possibilita a integração de recursos computacionais para a exploração dos tratamentos e das conversões dos registros de representação semiótica das cônicas (SIQUEIRA; BELLEMAIN, 2018).

O método para o desenvolvimento do novo micromundo está baseado na Engenharia Didático-Informática (EDI) (TIBÚRCIO, 2016), que reúne elementos da Engenharia de Software (ES). Essa, consoante Benitti, Seara e Schlindwein (2005), organiza certa estrutura para o processo de desenvolvimento de um software em algumas etapas: concepção, elaboração, finalização e viabilização. Também utiliza os elementos da Engenharia Didática ${ }^{8}$ (ARTIGUE, 1996): análises preliminares e suas dimensões didática, cognitiva e epistemológica; a fase de análise a priori; a experimentação; a análise a posteriori e a validação. Essa articulação é explicitada por Tibúrcio (2016) da seguinte maneira:

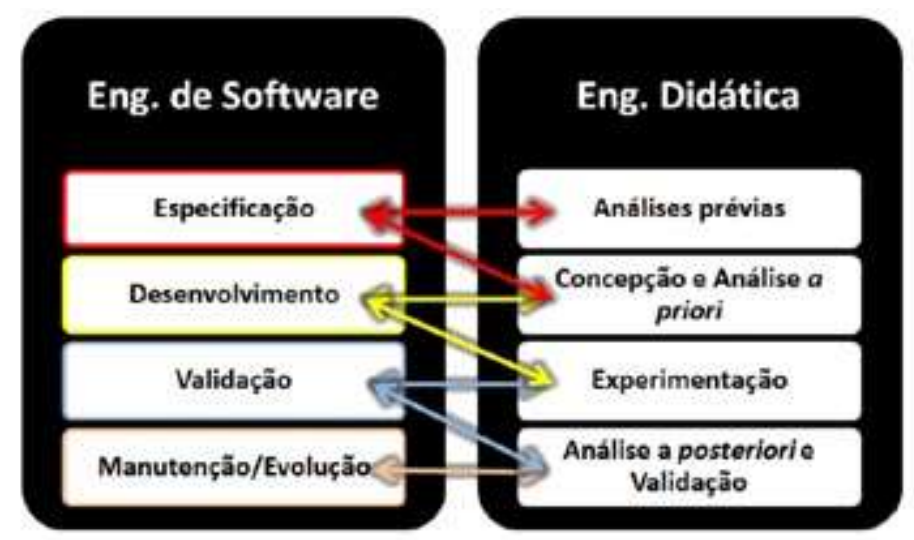

Figura 1: Articulação entre as Engenharias Fonte: (TIBÚRCIO, 2016, p. 46).

\footnotetext{
${ }^{8}$ A engenharia didática caracteriza-se por um esquema experimental baseado em "realizações didáticas" na sala de aula, isto é, na concepção, na realização, na observação e na análise de sequências de ensino (ARTIGUE, 1996, p. 196).
} 
Por meio dessa ilustração, Tibúrcio (2016) faz uma relação das fases que compõem as duas engenharias. Ele explica que os processos de desenvolvimento de software podem ser designados nas quatro etapas explicitadas acima (especificação, desenvolvimento, validação, Manutenção/Evolução) da ES, enquanto que as etapas da ED servem de fundamentação teórica e metodológica para o desenvolvimento de SE (software educativo). Em resumo, esse autor explica as relações entre as fases das engenharias, ilustradas na figura acima, da seguinte forma:

A etapa de Especificação: momento em que se define a tipologia do software, requisitos e características (relaciona-se com as análises inicias da Engenharia Didática).

A etapa de Desenvolvimento: leva em consideração o levantamento teórico que foi realizado na Concepção e Análise a priori e nesse momento é iniciado o processo de experimentação do software.

O processo de Validação do software: relaciona-se com a experimentação da ED e com a última fase, a análise a posteriori e validação. Validar o software significa verificar se o mesmo realiza o que se propõe a fazer.

A etapa de manutenção/evolução: relaciona-se com a análise a posteriori e validação no momento em que a análise comparativa fornecida pela ED, traz à tona elementos que servem para o aperfeiçoamento e evolução do software desenvolvido. (TIBÚRCIO, 2016, p.47).

Neste texto, em virtude de ser um recorte, no qual objetivamos explicitar uma parte do percurso de concepção e desenvolvimento do Magnitude Studium, nos debruçamos apenas em alguns elementos do modelo de desenvolvimento de software da EDI, são eles: a delimitação do campo a qual restringimos aos conceitos de área e perímetro; das análises preliminares as dimensões cognitiva e didática que nos permitiram elencar requisitos referente a área e perímetro a serem implementados no micromundo; a prototipação e breve análise do funcionamento do protótipo. Apresentamos a seguir, cada uma dessas fases.

\section{Estudos Didático e Cognitivo de Área}

Como explicitamos anteriormente, para se desenvolver um software educativo de boa qualidade utilizando-se o modelo de desenvolvimento proposto na EDI, deve-se no primeiro momento, definir o campo de conceitos matemáticos que o software abordará. Decidimos então, continuar nossos estudos (SILVA, 2016) relativos à abordagem de área como grandeza (DOUADY; PERRIN-GLORIAN, 1989). A escolha por este recorte se deu pelas influências da participação do autor deste texto no grupo de pesquisa Pró-Grandezas, o qual vem investigando, há mais de 15 anos, os fenômenos relativos ao ensino e aprendizagem das grandezas e medidas em vários níveis escolares, com foco nas grandezas geométricas: área, comprimento, perímetro, volume e capacidade (BELLEMAIN; LIMA, 2002).

\section{Abordagem de área como Grandeza}

A proposta de abordar área como uma grandeza nesta pesquisa apoiou-se nos estudos desenvolvidos por Douady e Perrin-Glorian (1989). Essas autoras evidenciaram erros e entraves na resolução de problemas sobre área por alunos franceses em um nível 
equivalente ao $4^{\circ}$ e $5^{\circ}$ anos do ensino fundamental no Brasil em 1980, dentre os quais, destacam-se que:

- a possibilidade de expressar a área de uma figura usando certa unidade depende dos formatos da figura e da superfície unitária, ou seja, da possibilidade de ladrilhar efetivamente a figura com uma quantidade finita de exemplares da superfície unitária. Assim, encontram dificuldade em expressar a área de um triângulo em centímetros quadrados devido à impossibilidade de cobrir um triângulo efetivamente com uma quantidade finita de quadradinhos de lados de um centímetro;

- a área de uma figura é ligada à própria figura de tal modo que não se dissocia de outras características da mesma. Nessas condições, não parece possível, aos olhos dos alunos, modificar uma figura, mantendo sua área inalterada, ou seja, qualquer modificação da figura modificaria necessariamente sua área e todas as demais características da figura (como seu perímetro, por exemplo);

- qualquer modificação do perímetro de uma figura altera sua área (e reciprocamente);

- duas figuras que tenham áreas iguais têm necessariamente perímetros iguais (e reciprocamente);

- o uso de certas fórmulas pode ser estendido a situações nas quais não são válidas, como é o caso de multiplicar os comprimentos dos lados adjacentes de um paralelogramo não retângulo ou até multiplicar os comprimentos dos três lados de um triângulo (estendendo indevidamente a validade da fórmula da área de um retângulo).

Pesquisas realizadas no Brasil em diferentes níveis de escolaridade (BELLEMAIN; LIMA, 2002; DUARTE, 2002; FACCO, 2003; FERREIRA, 2010; FERREIRA; BELLEMAIN, 2013, SILVA; BELLEMAIN, 2017, entre outros) identificaram erros e dificuldades similares aos apresentados nos estudos das pesquisadoras francesas. Tais pesquisas destacaram que "grande parte dos estudantes cometem erros em relação ao uso de unidades de medida e alguns consideram que figuras com áreas iguais são necessariamente congruentes" (SILVA, 2016, p. 24).

Para Ferreira e Bellemain (2013), o modelo explicativo para tais entraves, proposto por Douady e Perrin-Glorian (1989) e adotado por Baltar (1996), baseia-se na organização das concepções dos estudantes em dois polos - as concepções geométricas e as concepções numéricas - as quais são descritas da seguinte forma:

As concepções geométricas se caracterizam por um amálgama entre a figura e a área, ou seja, para os sujeitos que mobilizam uma concepção geométrica é como se a palavra área remetesse à própria figura e não a uma propriedade da mesma. No outro extremo, estão as concepções numéricas, que focam exclusivamente o aspecto do cálculo. É o caso de respostas a problemas de cálculo de área, nas quais nenhuma unidade é mencionada ou utilizam-se unidades inadequadas. (FERREIRA; BELLEMAIN, 2013, p. 3).

Douady e Perrin-Glorian (1989) enfatizam que os estudantes mobilizam ora uma concepção geométrica de área, ora uma concepção numérica e, por vezes, as duas de forma simultânea, mas sem estabelecer relações pertinentes entre os aspectos geométricos e numéricos no tratamento de problemas sobre área, o que provoca ou reforça a persistência de dificuldades na aprendizagem da área. Ainda colocam que um dos motivos 
que enfatizava essas concepções estava relacionado ao modelo de ensino nos níveis elementares na França na década 80. Para elas:

A apresentação padrão do ensino consiste em recorrer ao ladrilhamento de superfícies passando-se rapidamente pelo ladrilhamento e contagem dos quadrados para determinar a área de superfícies quadriculáveis; em seguida, para retângulos ou quadrados, procuram-se meios econômicos de contagem; depois, procede-se à introdução das unidades convencionais com múltiplos e submúltiplos e, de acordo com o caso, antes ou depois disso, leva-se ao estabelecimento das fórmulas de áreas dos retângulos em função dos comprimentos dos lados (DOUADY; PERRIN-GLORIAN, 1989, p. 393-Tradução Livre).

A partir dessa constatação, essas autoras defendem que na aprendizagem do conceito de área devem-se considerar três quadros: o geométrico, o numérico e o das grandezas. Para elas "um quadro é constituído de objetos de um ramo da matemática, das relações entre esses objetos, de suas formulações eventualmente diversas e das imagens mentais que o sujeito associa num dado momento, a esses objetos e relações" (DOUADY; PERRINGLORIAN, 1989, p. 389- Tradução Livre).

No quadro geométrico, estão as superfícies planas, consideradas como modelos matemáticos de faces de objetos do mundo físico. São objetos desse quadro, triângulos, quadriláteros, círculos, figuras de contornos irregulares, etc. Esses objetos geométricos são comparados segundo o atributo área. Nesse modelo, a área faz parte do quadro das grandezas e é caracterizada como classe de equivalência de superfícies de mesma área. O quadro numérico é composto pelas medidas, as quais são números reais não negativos $\left(3, \frac{1}{7}, \sqrt{5}\right.$, etc.). Expressões compostas de um número acompanhado de uma unidade de área são maneiras de representar grandezas (3 ha, $\frac{1}{7} \mathrm{~m}^{2}, \sqrt{5} \mathrm{~km}^{2}$, etc.). (SILVA; BELLEMAIN, 2017, p. 4).

A concepção e experimentação de uma engenharia didática realizada nos estudos das pesquisadoras francesas supracitadas evidenciaram que a abordagem de área como grandeza favorecia a construção de relações entre conhecimentos geométricos e numéricos na resolução de problemas de área. Ainda para essas autoras a distinção e a articulação entre três quadros, a saber: o geométrico, o numérico e o das grandezas contribuem para a construção do conceito de área como grandeza.

\section{Perímetro}

Os estudos de Barbosa (2002), Brito (2003) e Brito e Bellemain (2004) explicitam que o perímetro se trata de um instanciamento da grandeza comprimento, ou seja, "um caso particular da grandeza comprimento, diferenciando-se do objeto geométrico, em si, que é uma linha fechada" (BARBOSA, 2002, p. 32). Esse autor supõe ainda, a partir da abordagem de área, que a distinção e articulação entre os quadros geométrico, numérico e das grandezas favorece a construção do conceito de comprimento, ou de perímetro em particular.

Nesta perspectiva do quadro geométrico participam as linhas abertas ou fechadas essa última constituindo-se o que chamamos de contorno de uma figura plana, poligonal 
ou não. O comprimento faz parte do quadro das grandezas e caracteriza-se de forma distinta das linhas, pois, diferentes linhas podem possuir o mesmo comprimento e por último, o quadro numérico é composto das medidas de comprimento usando diferentes unidades (BRITO; BELLEMAIN, 2004, p. 5).

Para Barbosa (2002), deve-se dar ênfase ao se introduzir esses conceitos à distinção e à articulação entre o quadro geométrico e o das grandezas, que significa, em especial, comparar comprimentos sem medir, sem fazer intervir o quadro das medidas, ou numérico. Ainda para esse autor é importante construir o conceito de perímetro de forma mais ampla do que é adotado em muitos manuais didáticos, nos quais, segundo ele, se diz quase sempre que o "perímetro é a soma dos lados". Também assentimos que tal definição parcial pode gerar um obstáculo didático ${ }^{9}$ para a compreensão de figuras não poligonais, tão importantes para a matemática e para a vida prática.

Na próxima subseção apresentaremos pesquisas que utilizaram diferentes recursos ${ }^{10}$ como forma de permitir a articulação entre os três quadros supracitados, objetivando contribuir com a superação das concepções geométricas e numéricas de área por parte dos estudantes da educação básica, como também o amálgama entre área e perímetro.

\section{Diferentes recursos no ensino e aprendizagem de área e perímetro ${ }^{11}$}

Pesquisas em educação matemática realizadas no Brasil já há algum tempo têm se debruçado sobre as potencialidades do uso de diferentes recursos como forma de permitir a articulação entre os três quadros explicitados anteriormente como os estudos de (DUARTE, 2002, FACCO, 2003).

Duarte (2002) realizou uma investigação exploratória, a partir de um estudo de caso com um grupo de 73 alunos da $5^{a}$ série do ensino fundamental anos finais (atualmente, $6^{\circ}$ ano), de uma escola da rede pública estadual. Desses alunos, foram selecionadas quatro duplas. Tendo como aporte teórico a Teoria dos Campos Conceituais, o autor elencou como objetivo no seu estudo diagnosticar noções, procedimentos, invariantes operatórios (teoremas em ação e conceitos em ação) que seriam mobilizados por estes sujeitos na resolução de um conjunto de atividades relacionadas às situações que dão sentido a área desenvolvidas por Baltar (1996), a saber: comparação de área, medida de área e produção de superfície.

Nessas situações pesquisadas o autor explorou dois tipos de abordagem: a primeira centrada em atividades relacionadas a objetos dos quadros geométricos e das grandezas sem numerização e, a segunda, apresentando atividades envolvendo objetos dos quadros numérico, geométrico e das grandezas com unidades de medidas não convencionais. Para responder as atividades propostas, o pesquisador entregou alguns materiais para os estudantes, dentre eles: malhas quadriculadas, triangulares e o tangram.

\footnotetext{
${ }^{9}$ Conhecimentos que se encontram relativamente estabilizados no plano intelectual e que podem dificultar a evolução da aprendizagem do saber escolar" (PAIS, 2001, p.44).

${ }^{10}$ Nossa concepção de recurso está apoiada nos estudos de Jill Adler (2000) que os conceitua como sendo tudo que "realimenta", "reconfigura" (re-source) a atividade do professor.

${ }^{11}$ As pesquisas analisadas nesta subseção foram escolhidas pelo fato dos autores terem utilizado em seus estudos a abordagem de área como grandeza.
} 
$\mathrm{Na}$ atividade 04 da $2^{\circ}$ seção, intitulada "trabalhando com o tangram", o objetivo foi investigar a ação do estudante em uma situação em que deveria perceber a comparação das áreas por sobreposição, decomposição/recomposição, pela mudança de unidade de área e as relações entre as áreas e das peças causadas por essa mudança. Foi observado que os estudantes não tiveram dificuldades pelo fato de poderem manusear diferentes peças desse quebra-cabeça de forma dinâmica, mostrando compreender que figuras com formas diferentes podem ter a mesma área e que uma mesma figura pode possuir medidas diferentes a depender da unidade de medida utilizada, mas que a área permanece invariável.

Com relação ao uso das malhas, ora é possível observar que as figuras construídas sobre elas são pintadas (em que não é possível verificar de forma direta os quadradinhos que a compõe), ora as figuras são desenhadas e os quadrados que a compõem destacamse na malha. Sobre essas duas variáveis controladas pelo autor, pode-se observar que, particularmente, o contexto de papel quadriculado ou triangular parece ser um ambiente que favorece a resolução de problemas envolvendo medida, uma vez que os procedimentos adotados nas atividades em papel quadriculado ou triangulado foi quase sempre o esperado, ou seja, a contagem de unidades para em seguida estabelecer as áreas.

Assim como Duarte (2002), que utilizou o tangram e as malhas como meio para diagnosticar dificuldades na aprendizagem de área, Facco (2003) também fez uso desses recursos em seu estudo sobre a abordagem de área como uma grandeza. Como suporte teórico, essa autora utilizou a dialética ferramenta-objeto e mudanças de quadro Régine Douady (1986) e a teoria dos registros de representação semiótica de Duval (1993). Tendo como objetivo os estudos dos fenômenos que interferem no processo de ensino aprendizagem do conceito de área no ensino fundamental, apresentou uma proposta para o ensino do conceito de área por meio de uma sequência didática envolvendo a decomposição e recomposição de figuras planas. Os sujeitos de sua pesquisa foram estudantes e professores do ensino fundamental.

Em uma das atividades dessa sequência, a autora utilizou tanto malhas quadriculadas como triangulares. Segundo essa autora, a mudança de malha é uma escolha didática que intenciona a identificação de diferentes unidades de medida de área. $E$, quando essas unidades estão destacadas na malha, os estudantes tendem a contar os quadradinhos ou triângulos que expressarão a medida da área das figuras. Na atividade das malhas, diferente de Duarte (2002) que utiliza apenas figuras poligonais no estudo das áreas, Facco (2003) traz figuras não poligonais como apresentamos na ilustração abaixo:

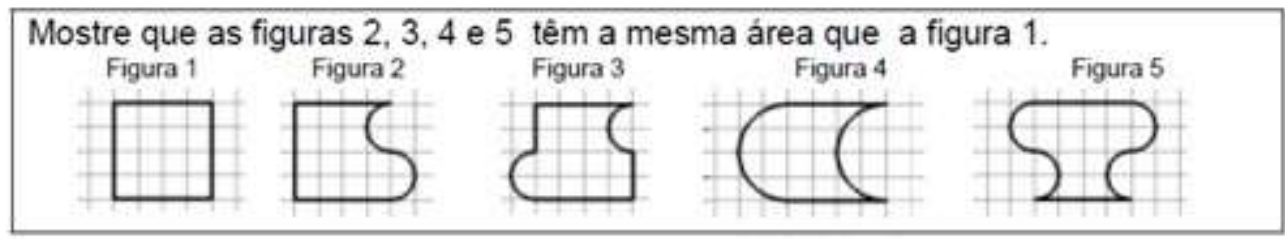

Figura 2: Figuras poligonais e não poligonais nas malhas Fonte: Facco (2003, p. 65)

Ela ainda coloca que essa atividade na malha quadriculada poderia ajudar os estudantes a responderem, utilizando a técnica de compensação (composição e decomposição) ou a contagem para justificarem que existem figuras com mesma área, mas 
com formas diferentes. Como previsto, $87,5 \%$ dos estudantes responderam utilizando o método da compensação (decomposição e recomposição) e 22,5\% dos alunos contaram a quantidade de quadradinhos para responderem essa atividade.

Com relação ao uso do tangram, Facco (2003) realizou atividades que permitiram aos estudantes em sua pesquisa construírem (montarem) diferentes figuras em posições diversas com as peças desse jogo. Essa possibilidade ofereceu condições para que eles percebessem a invariância da área por isometrias, que os formatos das figuras podem mudar e a área se manter invariável, como também à composição de diferentes figuras com as mesmas peças do tangram unidas pela justaposição de seus lados pode ter o perímetro reduzido ou aumentado.

Outro resultado que pode ser identificado nessa atividade diz respeito à composição de duas figuras, ou seja, a medida da área da figura montada é a soma das medidas das áreas das duas figuras que a compõem (peças do tangram) e que o perímetro é a soma das medidas dos lados da figura final. Facco (2003), concluindo sua pesquisa, coloca que a proposta para o ensino e aprendizagem de área desenvolvida em seu estudo é satisfatória e pode ser confirmada por meio da aplicação da sequência de atividades realizadas com o uso de diferentes recursos, como os que foram apresentados.

As pesquisas explicitadas anteriormente nos permitiram refletir que as malhas quadriculadas e triangulares, o tangram e os poliminós produzidos e utilizados em papel, borracha, plástico, madeira (ambientes não digitais) e a possibilidade de decompor e recompor figuras mostraram-se pertinentes para o ensino e aprendizagem de área e perímetro. Pretendemos, então, implementar tais recursos em um micromundo e verificar suas possíveis potencialidades para o estudo desses conceitos.

\section{Dimensão Operacional}

\section{Elicitação de Requisitos}

Para a elicitação e análise de requisitos do novo micromundo denominado de Magnitude Studium (MS), subsidiamo-nos em elementos da fase de análise preliminar (dimensão teórica), conforme o modelo de Tibúrcio (2016). Em nossa tese (SILVA, 2019) foram consideradas todas as dimensões de forma bem aprofundada, mas, pelas limitações deste tipo de texto, escolhemos focar apenas nas dimensões cognitiva e didática das quais extraímos os requisitos pertinentes para o trabalho da abordagem de área e perímetro.

Com tais requisitos elencados, tivemos a primeira interação com o programador. 0 objetivo foi explicitar as funcionalidades de cada uma delas de forma mais enfática. O engenheiro-programador ${ }^{12}$ responsável pelo desenvolvimento do MS, além do conhecimento da parte de ESE (Engenharia de Software Educativo) tem formação em Didática da Matemática. As sugestões dadas por ele nos permitiram redirecionar o olhar para um protótipo que pudesse ser desenvolvido em um tempo hábil para testagem e que permitisse tratar da abordagem de área como uma grandeza. Para isso, refinamos os

\footnotetext{
${ }^{12}$ O engenheiro responsável pelo desenvolvimento do software é o professor Dr. Franck Bellemain um dos autores desta pesquisa.
} 
requisitos, a fim de viabilizarmos a primeira versão desse software explicitada na ilustração a seguir:

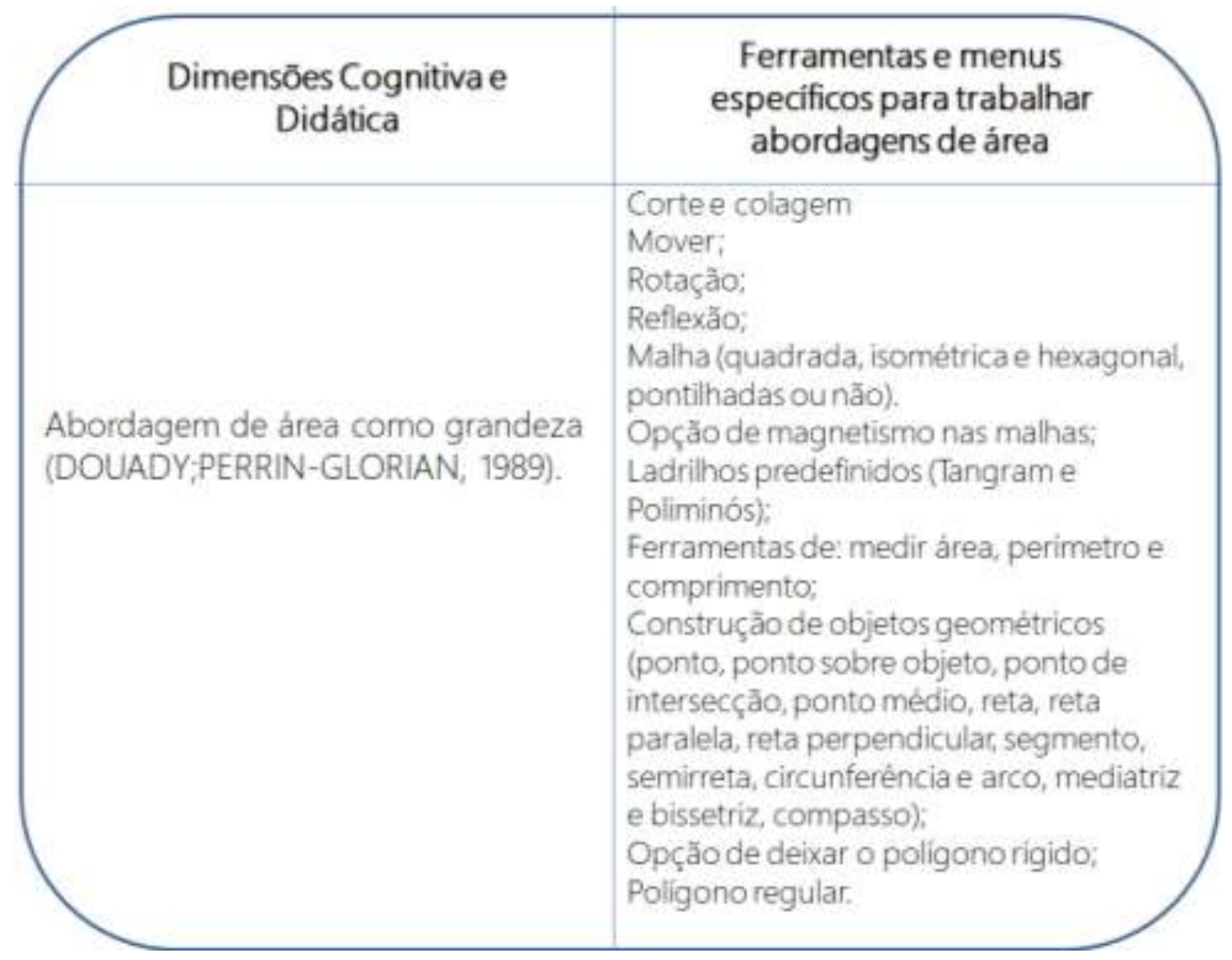

Figura 3: Requisitos para MS

Fonte: desenvolvido pelos autores desta pesquisa

\section{Desenvolvimento da primeira versão do protótipo}

Optamos por desenvolver o Magnitude Studium para plataforma web utilizando as linguagens HTML (HTML5), CSS e JAVA SCRIPT. Para Tibúrcio (2016), essas linguagens de programação podem ser interpretadas como um padrão por qualquer browser e editadas por meio de tratamento de texto. São beneficiadas por meio de inúmeras bibliotecas de objetos, o que possibilita diminuir o tempo de desenvolvimento. Outro fator que nos levou a pensar no desenvolvimento do MS para plataforma web foi à facilidade de uso pelos professores. Muitas vezes, há certa preocupação com o tipo de sistema operacional e hardware dos computadores no laboratório de informática das escolas e essa situação tem impossibilitado a exploração de diferentes software nas aulas de matemática (SILVA, 2016).

Nesta parte do desenvolvimento levamos em conta também a implementação de interfaces, que é a parte do sistema que diz respeito aos processos computacionais necessários para: controle dos dispositivos de hardware, construção de objetos de interface (os widgets) com os quais o usuário pode interagir; a geração dos vários símbolos e mensagens que representam a informação do sistema e a interpretação dos comandos do usuário. 


\section{Primeira versão do protótipo ${ }^{13}$}

Após as especificações supracitadas, o engenheiro-programador nos enviou um layout com os ícones associados às ferramentas já em funcionamento. Apresentamos a seguir a interface do MS desenvolvida para teste e experimentação, fases do modelo de Tibúrcio (2016). Logo após, explicitamos cada uma das ferramentas e suas funcionalidades.

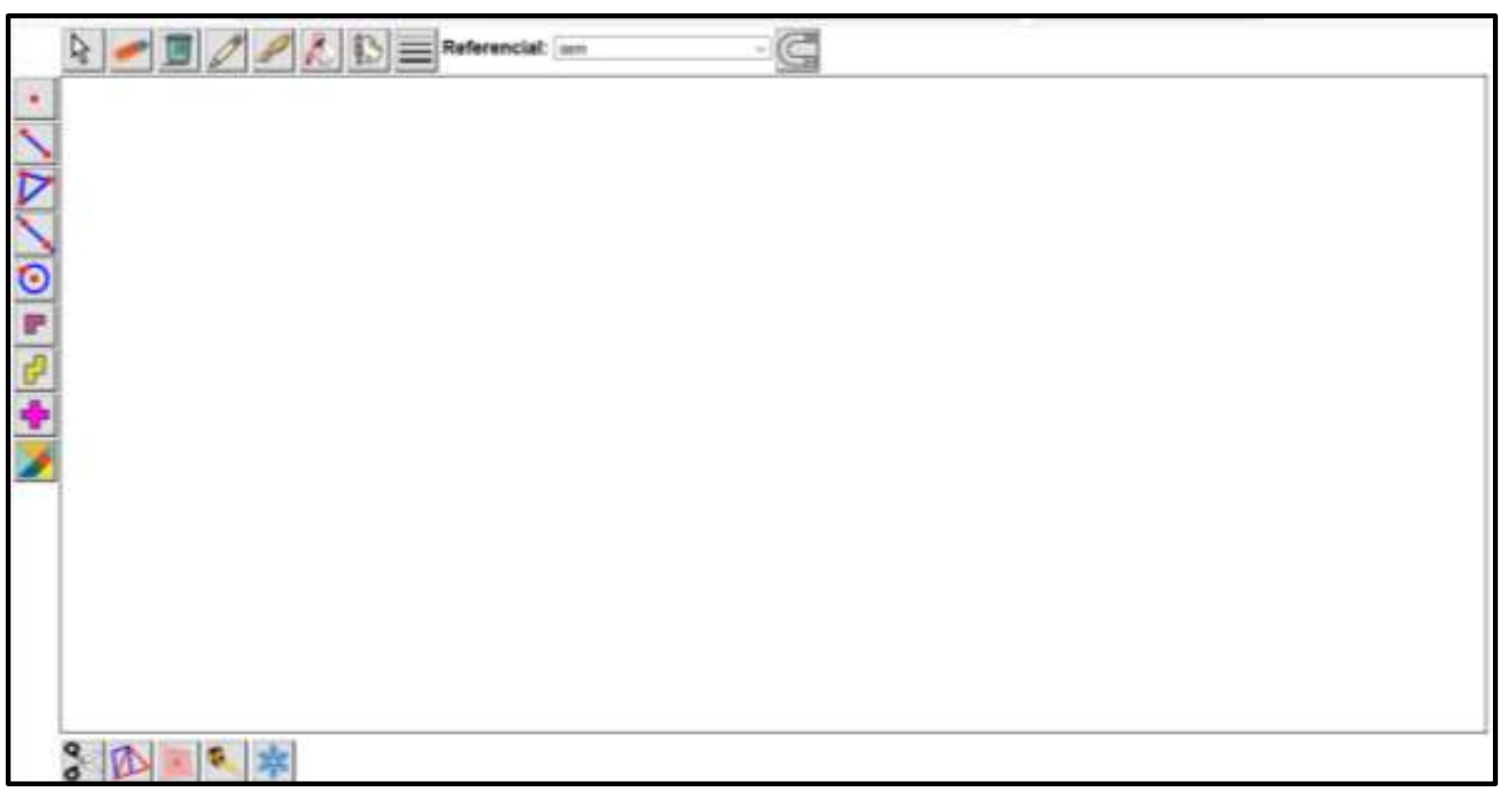

Figura 3: Layout do MS

Fonte: dos autores desta pesquisa

Na barra superior do software temos da esquerda para a direita as seguintes ferramentas:

- Ponteiro: move um objeto criado na interface e desabilita funções das ferramentas ativadas;

- Borracha: esconde um objeto e o faz aparecer na tela novamente;

- Lixeira: exclui os objetos construídos na interface do software;

- Lápis: oferece opções de contornos para retas e pontos (vértices e lados de diferentes polígonos);

- Pincel: permite colorir o contorno dos objetos, tais como vértices e lados das figuras;

- Latinha de tinta: função de preencher as figuras com diferentes cores;

- Aquarela de cores: oferece uma paleta de cores e níveis de transparência para colorir os lados das figuras anteriores a construção;

\footnotetext{
${ }^{13}$ Para o desenvolvimento do protótipo do MS não foi preciso organizar uma equipe multidisciplinar, pois o engenheiro pesquisador juntamente com o engenheiro programador já possuíam elementos suficientes para a construção do micromundo tanto no que diz respeito aos aspectos técnicos quanto pedagógicos. Vale ressaltar que o conhecimento referente aos integrantes da equipe multidisciplinar para o desenvolvimento de software foi acessado em nossas análises preliminares.
} 
- Estilos de linhas: permite escolher o estilo de linha desejado para as bordas das figuras;

- Referencial: oferece diferentes opções, tais como eixo, eixo e malha, malha (quadriculada, isométrica e hexagonal) e malha pontilhada (quadrada, isométrica e hexagonal);

- Imã: ativa ou desativa o magnetismo nas malhas.

Na barra lateral esquerda estão presentes algumas ferramentas que são comuns em alguns software de geometria dinâmica. Para visualizarmos as ferramentas embutidas é preciso dar um clique duplo no seu respectivo ícone, abrindo, assim, o menu de contexto. No primeiro, temos o ponto e o ponto médio. Logo abaixo, segmento e linha poligonal. No ícone representado por um triângulo estão contidas as seguintes ferramentas: (triângulos, quadriláteros, Paralelogramo, Quadrado, Retângulo, Polígono qualquer e Polígono Regular).

O próximo menu representado por uma reta contém, além desse objeto, as retas (paralela, perpendicular, mediatriz e bissetriz). Logo abaixo desse, temos a circunferência, circunferência por três pontos, arco e segmento circular. Em termos de interface, as funcionalidades dessas ferramentas seguem os princípios da geometria dinâmica do software Cabri, por exemplo. Ainda na barra lateral esquerda, temos os ladrilhos predefinidos, ou seja, as peças do jogo poliminós. Para trazê-las diretamente a tela do software é preciso dar um clique duplo no ícone que representa o desenho das peças, e, em seguida, escolher uma delas (monominó, dominó, triminó, tetraminó ou pentaminó). Após isso, basta clicar na área de trabalho do software que a mesma aparecerá.

A última ferramenta da barra lateral é o tangram. Diferente dos poliminós, as peças desse jogo não ficam embutidas no ícone correspondente. Para ter acesso a elas, será preciso construir um quadrado localizado no menu que contém os polígonos e, logo depois, premir o botão tangram e, em seguida, um dos segmentos do quadrado.

$\mathrm{Na}$ barra inferior do software temos o ícone "tesoura". Ao clicarmos nele, abrirá um menu de contexto contendo as ferramentas de corte e colagem. A primeira da esquerda para direita permite cortar qualquer polígono. A segunda e a terceira são programadas para triangularizar os polígonos construídos (decompor os polígonos em triângulos) e a última, nesta ordem, permite colar as figuras. As funcionalidades dessas ferramentas dão conta da decomposição e recomposição de figuras, procedimentos pertinentes no estudo de área de figuras planas como fora apontado em seções anteriores.

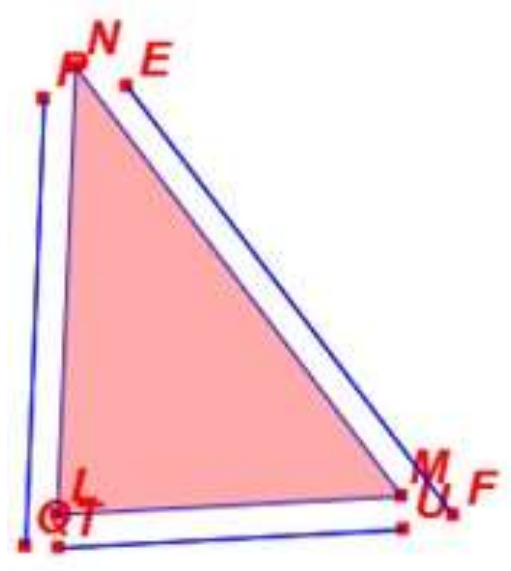

Figura 4: Decomposição dos lados das figuras. Fonte: da pesquisa 
A ferramenta de corte ainda fornece condições ao usuário de destacar os lados das figuras para utilizá-las como uma unidade de medida não convencional de comprimento. Conforme a figura 4.

Os lados destacados podem ser movidos, rotacionados e coloridos. Para realizar o procedimento denominado de "decomposição dos lados das figuras" é preciso selecionar a ferramentas decompor (tesoura), escolher um dos vértices da figura, clicar nele, e em seguida no próximo, do lado da figura que se deseja destacar. Automaticamente, o software separa o segmento. A figura permanecerá sem nenhuma alteração, podendo ser aproveitada para outras operações. Conjecturamos que as ferramentas apresentadas nesta seção podem ser um importante suporte ao professor para o ensino e aprendizagem de área e perímetro de figuras planas.

\section{Considerações finais}

O Magnitude Studium foi pensado desde sua concepção em dar suporte ao professor para o ensino de área e perímetro em um ambiente informático, mais precisamente um micromundo dinâmico, visto que ao longo dos anos, pesquisas em Educação Matemática vêm apontando dificuldades na aprendizagem de alunos das mais variadas etapas da educação básica referente ao conceito de área e perímetro (DUARTE, 2002, FACCO, 2003, FERREIRA, 2010, SILVA, 2016) dentre elas: a confusão entre área e a figura, área e sua medida e área e perímetro.

Entendemos a partir das pesquisas de Douady e Perrin-Glorian (1989) que alguns elementos são pertinentes no estudo do conceito de área e úteis na superação de tais dificuldades: distinguir a área da figura (já que figuras distintas podem ter mesma área), a área de uma figura de suas diferentes medidas, usar superfícies unitárias diversas para a medição da área de figuras e distinguir a área de uma figura do seu perímetro (PRATES, 2011).

Para trabalhar com a distinção entre área e figura, no MS, o professor pode permitir aos estudantes a utilização das diferentes ferramentas de decomposição para que eles percebam que a decomposição e recomposição de figuras sem perda nem sobreposição conserva a área.

Ainda com relação à contribuição para tal distinção, podem ser usadas as ferramentas que permitem a construção de figuras, com as quais, o professor pode construir situações de aprendizagem, em que dada uma figura, pede-se que os alunos construam outras diferentes, mas que possuam área maior, menor e de mesma área que a figura dada. Uma forma de oferecer condições para que eles superem as concepções geométricas de área.

Com relação à distinção entre a área e sua medida, o professor pode contar com as peças do Tangram e dos Poliminós. Nesta dissociação, tem-se a possibilidade de uma mesma figura ter sua área medida por unidades de medidas diferentes, o que resulta em números (medidas) distintos para a área da mesma figura que não se altera. Quanto à dissociação entre área e perímetro, temos no software a possibilidade de trabalhar por meio dos poliminós a ideia de figuras geométricas com mesma área, mas que nem sempre preservam o mesmo perímetro. São várias as possibilidades que o usuário professor pode utilizar no MS para contribuir com a aprendizagem de área e perímetro como as apresentadas nos parágrafos anteriores. 
Como explicitamos em nossa introdução, a ideia o desenvolvimento deste novo software do tipo micromundo, parte das experiências com o AG2. Entretanto, temos um avanço do MS em relação a esse software. Um dos diferenciais é a possibilidade de decomposição. No MS, esse procedimento pode ser realizado de quatro maneiras diferentes: A primeira é selecionando o ícone "tesoura", em seguida, ir clicando com o botão esquerdo do mouse na parte da figura que se deseja decompor, iniciando por uma de seus lados ou vértice. Automaticamente, o software vai criando pontos para realizar ao final o corte. A decomposição será efetivada quando o usuário der um clique final em qualquer um dos lados ou vértices que compõem a figura. A segunda e a terceira estão relacionadas à decomposição de polígonos em triângulos. A quarta e última diz respeito ao jogo tangram, cujo princípio é recortar um quadrado nas peças desse quebra-cabeça.

No Apprenti Géomètre 2 a decomposição pode ser efetuada pela diagonal, vertical, horizontal, ou de diferentes formas por meio da criação e ligação de pontos sobre a figura, mas para isso, o usuário terá que realizar vários procedimentos que não se mostraram ser intuitivos em nossa pesquisa (SILVA, 2016). Com relação à colagem (composição de figuras) só é possível no Apprenti Géomètre 2 se os vértices e um dos lados das partes de uma figura decomposta coincidirem com os vértices e lado da outra figura, caso contrário, a colagem não é realizada. No MS tentamos superar essa questão. O usuário pode realizar a recomposição de figuras da maneira que achar conveniente.

Ainda há muito no que avançar para a finalização deste protótipo, mas conjecturamos que o MS seguindo os princípios da EDI pode ser um ambiente rico em recursos, orientado para o trabalho de área e perímetro como grandezas, permitindo ao professor construir situações de aprendizagem que contribuam com a superação da concepção geométrica e numérica de área, bem como a amálgama entre área e perímetro.

\section{Referências}

ADLER, J. Conceptualising resources as a theme for teacher education. Journal of Mathematics Teacher Education, v. 3, n. 3, p. 205-224, 2000.

ARTIGUE, M. Engenharia Didática. In: BRUN, J. Didática das Matemáticas. Tradução de: Maria José Figueiredo. Lisboa: Instituto Piaget, 1996. Cap. 4. p. 193-217.

BALTAR, P. M. Enseignement et apprentissage de la notion d'aire de surfaces planes: une étude de l'acquisition des relations entre les longueurs et les aires au collège. 1996. Tese (Doutorado em Didática da Matemática), Université Joseph Fourier, Grenoble, França, 1996.

BARBOSA, P. R. Efeitos de uma sequência de atividades relativas aos conceitos de comprimento e perímetro no $2^{\circ}$ ciclo Ensino Fundamental. 214 f. Dissertação (Mestrado em Educação), UFPE, Recife, 2002.

BELLEMAIN, P. M. B.; LIMA, P. F. Um estudo da noção de grandeza e implicações no Ensino Fundamental. Ed. Geral: John A. Fossa. Natal: SBHMat, 2002.

BENITTI, F. B. V.; SEARA, E. F. R.; SCHLINDWEIN; L. M. Processo de Desenvolvimento de Software Educacional: proposta e experimentação. 2005. Disponível em: http://www.seer.ufrgs.br/renote/article/viewFile/13849/8025. Acesso em: 08 out. 2016. 
BRITO, A. F. de. Um estudo sobre a influência do uso de materiais manipulativos na construção do conceito de comprimento como grandeza no $2^{\circ}$ ciclo do Ensino Fundamental. 2003. 196 f. Dissertação (Mestrado em Educação), UFPE, Recife, 2003.

BRITO, A. F. de.; BELLEMAIN, P. M. B. Influência do uso de materiais manipulativos na construção da grandeza comprimento. 2004. In: VIII ENEM: Encontro Nacional de Educação Matemática, São Paulo. Anais eletrônicos... Recife, 2004. Disponível em: http://www.sbembrasil.org.br/files/viii/pdf/01/CC00073428450.pdf. Acesso em: 12 dez. 2018.

DOUADY, R; PERRIN-GLORIAN, M. J. Un processus d'apprentissage du concept d'aire de surface plane. Educational Studies in Mathematics. v.20, n.4, p. 387-424, 1989.

DUARTE, J. H. Análise de Situações Didáticas para a Construção do Conceito de Área, como Grandeza, no Ensino Fundamental. 2002. 150 f. Dissertação (Mestrado em Educação) Centro de Educação, Universidade Federal de Pernambuco, Recife, 2002.

DUVAL, R. Registres de représentation sémiotique et fonctionnement cognitif de la pensée. Annales de Didactique et de Sciences Cognitives, v.5. IREM de Strasbourg, 1993, p. 37-65.

FACCO, S. R. Conceito de área: uma proposta de ensino-aprendizagem. 2003. $185 f$. Dissertação (Mestrado em Educação Matemática)- Programa de Estudos Pós-Graduados em Educação Matemática, PUC/SP, São Paulo, 2003.

FERREIRA, L. de F. D. A construção do conceito de área e da relação entre área e perímetro no $3^{\circ}$ ciclo do ensino fundamental: estudos sob a ótica da teoria dos campos conceituais. 2010. 191f. Dissertação (Mestrado em Educação). Centro de Educação, Universidade Federal de Pernambuco, Recife, 2010.

FERREIRA, L. de F. D.; BELLEMAIN, P. M. B. Estratégias utilizadas por alunos do $6^{\circ}$ ano em questões da OBEMEP sobre as grandezas comprimento e área. 2013. Disponível em: http://sbem.web1471.kinghost.net/anais/ XIENEM/pdf/2899_1501_ID.pdf. Acesso em: 23 fev. de 2016.

PAIS, Luis Carlos. Didática da matemática: uma análise da influência francesa. Belo Horizonte: Autêntica, 2001.

PRATES, U. e S. A atividade orientadora de ensino como mediação no desenvolvimento de um jogo computacional. 2011. 141 f. Dissertação (Mestrado)- Programa de Pós-Graduação em Educação, Universidade Federal de São Carlos (UFSCar), São Carlos/São Paulo, 2011.

SANTANA, W. M. G. de.; SILVA, A. D. P. R. da.; BARROS, A. L. Área como grandeza geométrica: um estudo por meio do Apprenti Géomètre 2. In: ENEM: Encontro Nacional de Educação Matemática, São Paulo. Anais eletrônicos... São Paulo, 2016. Disponível em: http://www.sbem.com.br/enem2016/anais/pdf/7637_3323_ID.pdf. Acesso em: 26 jun. de 2019.

SILVA, C. T. J. da. A engenharia didático-informática na prototipação de um software para abordar o conceito de taxa de variação. 2016. 163 f. Dissertação de Mestrado (Programa de Pós-Graduação em Educação Matemática e Tecnológica - EDUMATEC). Recife, UFPE. 2016.

SILVA, A. D. P. R. da. Ensino e aprendizagem de área como grandeza geométrica: um estudo por meio dos ambientes papel e lápis, materiais manipulativos e no Apprenti Géomètre 2 no $6^{\circ}$ ano do ensino fundamental. 2016. 315 f. Dissertação (Mestrado em 
Educação Matemática e Tecnológica)- Programa de Pós-Graduação em Educação Matemática e Tecnológica, Universidade Federal de Pernambuco, Recife, 2016.

SILVA, A. D. P. R.; BELLEMAIN, P. M. B. A comparação de áreas de figuras planas em diferentes ambientes: papel e lápis, materiais manipulativos e no Apprenti Géomètre 2. Revista de Educação Matemática e Tecnológica Iberoamearicana, v.8, No 3, 2017.

SILVA, A. D. P. R. da. Prototipação, desenvolvimento e validação de um micromundo com suportes para o ensino de área e perímetro. 408 f. 2019. (Doutorado em Educação Matemática e Tecnológica)- Programa de Pós-Graduação em Educação Matemática e Tecnológica, Universidade Federal de Pernambuco, Recife, 2019.

SIQUEIRA, J. E.; BELLEMAIN, F. Dynamic Multirepresentational resource for conics. 2018. Disponível em: https://resources-2018.sciencesconf.org/resource/page/id/8. Acesso em: 12 set. 2018.

TCHOUNIKINE, P. Computer Science and Educational Software Design: A Resource for Multidisciplinary Work in Technology Enhanced Learning. Ed. Springer. 2011.

TIBÚRCIO, R. S. Processo de desenvolvimento de software educativo: um estudo da prototipação de um software para o ensino de função. 2016. 112 f. Dissertação de Mestrado (Programa de Pós-Graduação em Educação Matemática e Tecnológica - Edumatec). Recife, UFPE. 2016. 